\title{
Endurance fitness and blood lactate concentration during stepping exercise in untrained subjects
}

\author{
S. Richardson, BSc and A.E. Hardman, PhD
}

Department of Physical Education and Sports Science, University of Technology, Loughborough, Leicestershire

\begin{abstract}
The purpose of the present study was to explore the possibility that reference blood lactate concentrations, determined during stepping exercise, could be used to derive an index of endurance fitness. The traditional measure of endurance fitness, maximal oxygen uptake $\left(\mathrm{VO}_{2}\right.$ max) and the individual relationships between blood lactate concentration and submaximal $\mathrm{VO}_{2}$ were determined during stepping for 10 untrained males. $\mathrm{VO}_{2}$ max values were $48.7 \pm 5.1$ ml. $\mathrm{kg}^{-1} \cdot \mathrm{min}^{-1}$ (mean $\pm \mathrm{sd}$ ). The time to exhaustion during stepping at 80 per cent $\dot{\mathrm{VO}}_{2} \max (38.82 \pm 17.83 \mathrm{~min})$ provided an additional measure of endurance fitness. The per cent $\mathrm{VO}_{2}$ max at a blood lactate concentration of $4 \mathrm{mM}$ was correlated significantly with endurance time (rho $=0.75$, $\mathbf{P}<0.05$ ).

These results show that a submaximal step test can be used to determine oxygen uptake and per cent $\mathrm{VO}_{2}$ max at a reference blood lactate concentration. However, for this group of subjects, per cent $\mathrm{VO}_{2}$ max at a blood lactate concentration of $4 \mathrm{mM}$ showed only a modest correlation with endurance.
\end{abstract}

Keywords: Lactate, endurance, stepping exercise

\section{Introduction}

Regular, frequent exercise is associated with a number of health benefits including a reduced risk of coronary heart disease ${ }^{1}$ and an increased likelihood of maintaining desirable body weight ${ }^{2}$. Consequently, exercise is now promoted by a number of agencies concerned with health. In this regard fitness testing is commonly employed because it has a role to play in stimulating and sustaining commitment to the habit of exercise.

The traditional approach to fitness testing has been in terms of absolute performance. That is, it has either involved measuring performance itself or the major determinant of endurance performance, i.e. maximal oxygen uptake $\left(\mathrm{VO}_{2} \max \right)$. The importance of $\dot{\mathrm{VO}}_{2}$ max in dictating performance has been amply demonstrated by the good correlations between this parameter and, for example, two mile run time $e^{3}$ or 5 $\mathrm{km}$ run time $\mathrm{e}^{4}$. Fitness testing has developed in this way because well trained athletes obviously run fast and are known to possess high $\dot{\mathrm{VO}}_{2}$ max values.

Address for correspondence: Dr A.E. Hardman, Department of Physical Education and Sports Science, University of Technology, Loughborough, Leicestershire LE11 3TU

(C) 1989 Butterworth \& Co (Publishers) Ltd 0306-3674/89/030190-04\$03.00
Indeed, the most important aspect of the training response for initially sedentary individuals is an increase in $\dot{\mathrm{VO}}_{2}$ max.

However, for those individuals who are already active, the increases in $\mathrm{VO}_{2}$ max resulting from further training are invariably modest. In other words, differences in training status fail to account for the range of values observed in the population. This appears to be because $\mathrm{VO}_{2}$ max is profoundly constrained by heredity ${ }^{5}$.

Maximal oxygen uptake is therefore an insensitive index of training in already active individuals for whom performance continues to improve in the absence of increases in $\mathrm{VO}_{2}$ max. This is attributable to an increased ability to sustain a high proportion of $\dot{\mathrm{V}}_{2}$ max, a characteristic conferred by adaptations of skeletal muscle metabolism ${ }^{6}$. A more complete description of an individual's endurance fitness would therefore include, as an adjunct to the determination of $\dot{\mathrm{V}}_{2}$ max, some measure of the ability to sustain submaximal exercise. The purpose of the present study is to examine one approach to the problem of developing such a test.

Blood lactate concentration during exercise reflects the adaptive state of the muscle ${ }^{7}$. Consequently, with training, the oxygen uptake at a reference blood lactate concentration increases, both in absolute terms and relative to the individual's $\mathrm{VO}_{2} \mathrm{max}^{8}$. We have found a strong relationship between the relative exercise intensity (per cent $\mathrm{VO}_{2}$ max) at which a reference blood lactate concentration is attained, and endurance time at a given per cent $\mathrm{VO}_{2} \max ^{9,10}$. In other words, the per cent $\mathrm{VO}_{2}$ max at which an individual attains a reference blood lactate concentration reflects his ability to sustain a high proportion of his $\mathrm{VO}_{2} \max$, i.e. his endurance.

The present study attempted to answer two questions. First, does relative exercise intensity at a reference blood lactate concentration reflect endurance in a group of untrained individuals? Secondly, can stepping, a simple, cheap and non-intimidating form of exercise, be used to determine this index? In order to provide a link with traditional, performance-based tests of fitness a two mile run/walk test was also conducted.

\section{Methods}

Ten untrained males with no previous experience of exercise testing volunteered to act as subjects. The 
procedures and risks had first been explained to them. Their age, height and weight were (mean \pm sd) $20.57 \pm 2.78 \mathrm{yrs}, 1.770 \pm 0.040 \mathrm{~m}$ and $72.3 \pm 8.0 \mathrm{~kg}$ respectively.

After habituation to the experimental procedures, each subject performed five tests each on different days, namely a preparatory test, a stepping $\mathrm{VO}_{2} \max$ test, a sub-maximal incremental step test, an endurance step test and a two mile $(3218 \mathrm{~m})$ performance test. A single $0.395 \mathrm{~m}$ step was used for all subjects; the stepping rate was dictated by an electronic metronome (Zen-on metrina). One beat was used for each footfall, with four beats per ascent. Work was taken as the positive work done and calculated as the product of step height, ascents per minute and body weight.

The preparatory test was a four stage, continuous, incremental step test with four minutes at each work rate. This served to derive the relationship between submaximal oxygen uptake and work rate for each subject. Maximal oxygen uptake was taken as that measured during the final minute of an open-ended progressive step test to exhaustion, using three minutes at each work rate. Linear regression was then used to predict the work rates needed to elicit 60, 70, 80 , and 90 per cent of $\mathrm{VO}_{2}$ max for each individual.

The submaximal step test employed a sixteen minute protocol such that each subject stepped at 60 , 70,80 , and 90 per cent of his $\mathrm{VO}_{2}$ max. Blood lactate concentration was determined in duplicate fingerprick samples obtained pre-exercise and at 4, 8, 12, and 16 minutes. Expired air was collected during the preceding minute. Work rates were increased at 4:30, $8: 30$, and 12:30 minutes, allowing 30 seconds to complete blood sampling at each work rate. Endurance was determined as the time to exhaustion whilst stepping at an intensity equivalent to a given percentage (78.3 \pm 4.1 per cent) of $\mathrm{VO}_{2}$ max. Expired air collections were obtained at $5,10,20,30,60$ minutes and the final minute of the test, at exhaustion. Finger-prick blood samples were obtained pre-exercise and immediately after each expired air collection.

Expired air samples were collected using standard Douglas bag techniques and subsequently analysed for oxygen and carbon dioxide concentration using a mass spectrometer (Centronic MGA 200). Volumes were determined using a dry gas meter (ParkinsonCowan) which had previously been calibrated against a Tissot spirometer. The electrocardiogram was recorded from three chest electrodes by a cardiac monitor (Rigel Ltd) and heart rate was sampled by a microcomputer (BBC Model B) at five second intervals. Blood samples were deproteinized immediately after collection and stored at $-20^{\circ} \mathrm{C}$ before analysis for lactate concentration ${ }^{11}$.

Values for predicted $\mathrm{VO}_{2}$ max were also obtained from oxygen uptake and mean heart rate during the final minute of each submaximal work rate, using the Asstrand nomogram ${ }^{12}$. These values were then expressed relative to body weight. The mean of two or three values was recorded.

In addition to the laboratory tests subjects performed a two mile run on the university athletics track. Heart rates were recorded with a short range telemetry system (Polar Electro Sport Tester PE3000) and lap times and final time were recorded.

Non-parametric methods of statistical analysis were used as the assumptions of parametric methods could not be adhered to ${ }^{13}$. The five per cent level of confidence was adopted.

\section{Results}

A linear relationship was demonstrated between oxygen uptake and stepping cadence during submaximal exercise (Figure 1). Table 1 shows values for $\mathrm{VO}_{2}$ max, endurance time, two-mile run time and oxygen uptake at a blood lactate concentration of $4 \mathrm{mM}$.

The relative exercise intensity at a blood lactate concentration of $4 \mathrm{mM}$ (per cent $\mathrm{VO}_{2} \max (4 \mathrm{mM})$ ) was related to endurance time during stepping exercise (rho $=0.75, \mathrm{P}<0.05)$, but there was no relationship between $\dot{\mathrm{V}}_{2}$ max and this measure of endurance (rho $=-0.01)$. When predicted $\mathrm{VO}_{2}$ max was used to determine per cent $\mathrm{VO}_{2} \max (4 \mathrm{mM})$ the correlation with endurance was non-significant $(\mathrm{rho}=0.37)$. Pre-

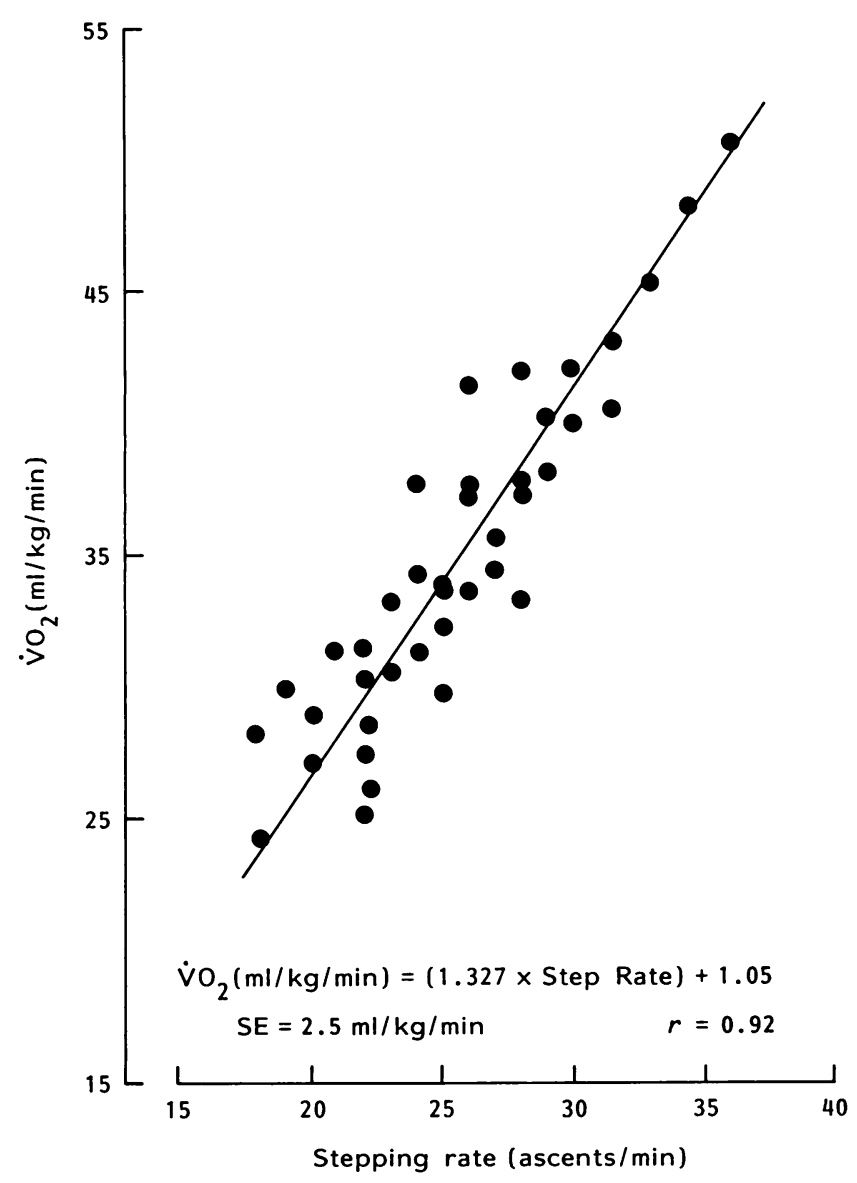

Figure 1. Oxygen uptake and stepping cadence during submaximal exercise

Table 1. Maximal oxygen uptake, endurance time at $80 \% \dot{\mathrm{VO}}_{2}$ max, two-mile run time and oxygen uptake at $4 \mathrm{mM}$ blood lactate concentration. (mean $\pm \mathrm{sd}, \mathrm{n}=10$ )

\begin{tabular}{|c|c|c|c|c|c|c|}
\hline & $\begin{array}{r}\dot{V O} \\
\text { (ml. } \mathrm{kg} \\
\text { measurec }\end{array}$ & $\begin{array}{l}\text { nax } \\
\left.\text { min }^{-1}\right) \\
\text { redicted }\end{array}$ & $\begin{array}{c}\text { En- } \\
\text { durance } \\
\text { (min) }\end{array}$ & $\begin{array}{l}\text { two-mile } \\
\text { run } \\
\text { (min) }\end{array}$ & $\begin{array}{l}\text { Oxygen } \\
\mathrm{VO}_{2} \max \end{array}$ & $\begin{array}{l}\text { iptake at } 4 \mathrm{mM}^{-1} \\
\mathrm{ml} \cdot \mathrm{kg}_{-1} \cdot \mathrm{min}^{-1}\end{array}$ \\
\hline $\begin{array}{l}\bar{x} \\
\text { sd }\end{array}$ & $\begin{array}{r}48.7 \\
5.1\end{array}$ & $\begin{array}{r}47.4 \\
9.7\end{array}$ & $\begin{array}{l}38.82 \\
17.83\end{array}$ & $\begin{array}{r}14.28 \\
2.00\end{array}$ & $\begin{array}{c}73.4^{*} \\
7.0\end{array}$ & $\begin{array}{c}35.8^{*} \\
5.5\end{array}$ \\
\hline
\end{tabular}

$*_{n}=9$ 


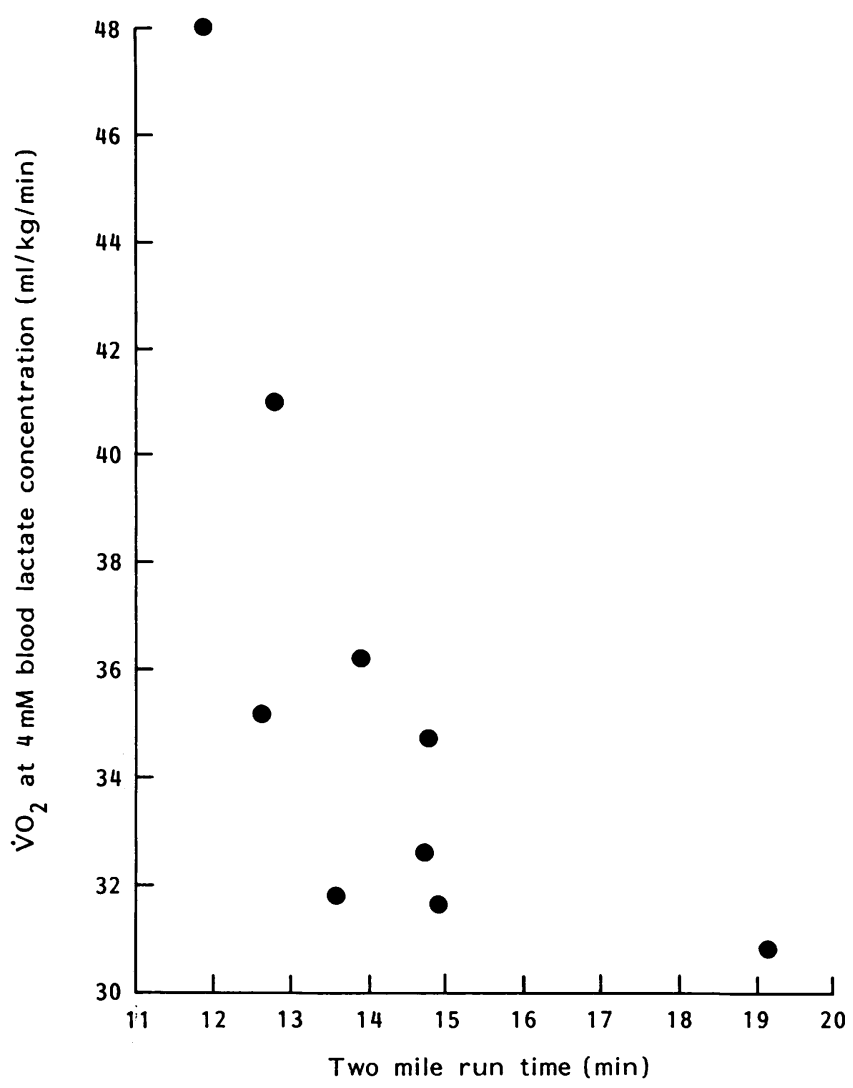

Figure 2. Correlation between oxygen uptake at blood lactate $4 \mathrm{mM}$ and two mile run time

dicted and measured maximal oxygen uptake values were correlated significantly (rho $=0.73, \mathrm{P}<0.05$ ).

Oxygen uptake at a blood lactate concentration of $4 \mathrm{mM}$ was correlated significantly with two-mile run time (Figure 2) (rho $=-0.82, P<0.01$ ), but neither $\mathrm{VO}_{2}$ max nor predicted $\mathrm{VO}_{2}$ max was correlated significantly with two-mile run time (rho $=-0.49$, rho $=-0.44$ respectively). Work rate and work rate per $\mathrm{kg}$ body weight at a blood lactate concentration of $4 \mathrm{mM}$ were both correlated significantly with two-mile run time (rho $=-0.82, P<0.01$ ).

\section{Discussion}

The purpose of the present study was to explore the feasibility of using reference blood lactate concentrations in a test of endurance fitness in untrained subjects. Stepping was the mode of exercise selected for this initial study as it is cheap, easily controlled and non-intimidating.

The mean values for $\dot{\mathrm{VO}}_{2} \max \left(48.7 \pm 5.1 \mathrm{ml} . \mathrm{kg}^{-1}\right.$. $\min ^{-1}$ ) were of the order expected for young, untrained males ${ }^{14}$ and clearly lower than those reported from our laboratory for physical education students of comparable age $\left(57.6 \pm 6.2 \mathrm{ml} . \mathrm{kg}^{-1} . \mathrm{min}^{-1}\right)^{4}$

The time to exhaustion at an intensity equivalent to a given per cent $\mathrm{VO}_{2}$ max constitutes a measure which allows the characteristics conferred by endurance training to be discerned even in individuals with modest $\mathrm{VO}_{2}$ max values. In the context of promoting exercise in the community this is important because it is regular exercise which benefits health, not the attainment of any absolute level of performance.
The significant correlation between endurance time and per cent $\dot{\mathrm{VO}}_{2} \max (4 \mathrm{mM})$ indicates that those individuals who were able to attain a high relative exercise intensity before blood lactate concentration reached $4 \mathrm{mM}$ tended to be those with the greatest endurance. This is consistent with the observation that training increases the relative exercise intensity at which reference blood lactate concentrations are attained ${ }^{15,16}$. Nevertheless, the observed correlation with per cent $\dot{V}_{2} \max (4 \mathrm{mM})$ accounted for only about 56 per cent of the variation in endurance, and further studies are clearly required before the determinants of endurance can be described more fully.

If a predicted $\mathrm{VO}_{2}$ max value, rather than that determined directly, could be employed to determine per cent $\mathrm{VO}_{2} \max (4 \mathrm{mM})$ then this index of endurance fitness could be obtained without recourse to maximal exercise. This would be attractive for reasons of subject motivation and safety. However, the low and nonsignificant correlation between this expression of per cent $\mathrm{VO}_{2} \max (4 \mathrm{mM})$ and endurance indicates that the errors introduced by predicting $\mathrm{VO}_{2}$ max reduced the usefulness of this measure in this group of subjects.

Although predicted and directly measured $\mathrm{VO}_{2}$ max values were correlated significantly, the correlation was only modest ( $r h o=0.73$ ). Investigations of the Åstrand nomogram ${ }^{12}$ have used a wide variety of protocols and exercise modes and found a wide range of correlations between predicted and measured values, e.g. from $r=39^{17}$ to $r=0.92^{18}$.

In the present study there was no relationship between $\dot{\mathrm{VO}}_{2}$ max and two-mile run time. There are several possible explanations for this finding. It may be that $\dot{\mathrm{VO}}_{2}$ max determined during stepping exercise does not relate to performance in a running task. Alternatively, for this group of subjects, the state of training may have been a more important determinant of running performance than $\dot{\mathrm{VO}}_{2} \max$ per se. This suggestion is supported by the significant correlation between the oxygen uptake at a blood lactate concentration of $4 \mathrm{mM}$ and two-mile run time (rho $=-0.82$ ).

Other workers have found oxygen uptake at a reference blood lactate concentration to be a better determinant of running performance than $\dot{\mathrm{VO}}_{2}$ max in some subject groups 19 . Strong correlations have also been reported between two-mile run time and the oxygen uptake at the onset of plasma lactate accumulation $^{3}$. These two studies measured blood lactate concentration during submaximal treadmill running. The results of the present study suggest that it may be possible to discern the metabolic consequences of habitual exercise during stepping exercise. This would have advantages in field testing because stepping is cheap, easily controlled and non-intimidating.

There is, however, one difficulty with using stepping exercise for determination of reference blood lactate concentrations. Our observations suggest that blood lactate concentration is somewhat low for a given relative exercise intensity during stepping exercise. For instance, one of the present subjects utilized some 82 per cent of his $\mathrm{VO}_{2}$ max during the final stage of the incremental test and still failed to reach the criterion blood lactate concentration. This experience is consistent with an earlier report which found blood lactate concentration to be higher in cycling than in running and higher in running than stepping, for a 
given relative exercise intensity 20 . This means that one has to exercise at rather a high proportion of $\mathrm{VO}_{2} \max$ before attaining a reference blood lactate concentration of $4 \mathrm{mM}$, provoking fears about subject safety in high risk populations. Future studies might therefore examine the usefulness of an alternative, non-intimidating form of everyday exercise such as walking in this approach to fitness testing.

Some running studies have found better correlations between speed at reference blood lactate concentrations and performance than between corresponding oxygen uptake values and performance ${ }^{3}$. For stepping exercise a parallel aproach would be to consider work rate or work rate per kg body weight at a blood lactate concentration of $4 \mathrm{mM}$. Work rate is easily controlled and measured in stepping. Despite the fact that stepping and running utilize difference muscle groups, both measures were well related to two-mile run time. Therefore either work rate or work rate per kg body weight at a reference blood lactate concentration could provide a description of functional capacity, the ability to perform work in absolute terms, which can be obtained without recourse to expired air analysis.

These results indicate that a submaximal step test can be employed to determine reference blood lactate concentrations. Furthermore, relative exercise intensity at a reference blood lactate concentration of $4 \mathrm{mM}$ was significantly related to submaximal endurance. For this group of subjects, oxygen uptake at a reference blood lactate concentration was a more important determinant of running performance over two miles than $\dot{\mathrm{VO}}_{2}$ max.

\section{References}

1 Morris, J.N., Pollard, R., Everitt, M.G. and Chave, S.P.W. Vigorous exercise in leisure time: Protection against coronary heart disease Lancet 1980, 80, 12071210

2 Weltman, A., Matter, S. and Stanford, B. Calorific restriction and/or mild exercise: effects on serum lipids and body composition Am J Clin Nutr 1980, 33, 10021009

3 Farrell, P.A., Wilmore, J.H., Coyle, E.F., Billing, J.E. and Costill, D.L. Plasma lactate accumulation and distance running performance Med Sci Sports 1979, 11, 338-344

4 Ramsbottom, R., Nute, M.G.L. and Williams, C. Determinants of five kilometre running performance in active men and women $\mathrm{Br} J$ Sports Med 1987, 21(2), 9-13

5 Klissouras, V., Pirnay, F. and Petit, J.-M. Adaptation to maximal effort: Genetics and age J Appl Physiol 1973, $35,288-293$
6 Gollnick, P.D., Armstrong, R.B., Saltin, B., Saubert IV, C.W., Sembrowich, W.L. and Shepherd, R.E. Effects of training on enzyme activity and fibre composition of human skeletal muscle J Appl Physiol 1973, 34, 107-111

7 Gollnick, P.D. and Hermansen, L. Biochemical adaptations to exercise. Anaerobic metabolism. Exercise and Sports Science Reviews, ed. Wilmore, J.H., 1973

8 Saltin, B. and Karlsson, J. Muscle ATP, CP, and lactate during exercise after physical conditioning Muscle metabolism during exercise, eds Pernow, B. and Saltin, B. London, Plenum, 1971

9 Williams, C. and Nute, M.G.L. Training-induced changes in endurance capacity of female games players. Sports Science, Proceedings of the VIII Commonwealth and International Conference on Sport, Physical Education, Dance, Recreation and Health, eds Watkins, J., Reilly, T. and Burwitz, L. London, E. and F.N. Spon. 1986

10 Mayes, R., Hardman, A.E. and Williams, C. The influence of training on endurance and blood lactate concentration during submaximal exercise $\mathrm{Br} J$ Sports Med 1987, 21, 119-124

11 Maughan, R.J. A simple rapid method for determination of glucose, lactate, pyruvate, alanine, 3-hydroxybutyrate and aceteacetate on a simgle $20 \mathrm{ul}$ blood sample Clin Chim Acta 1982, 122, 231-240

12 Åstrand, I. In Åstrand, P.-O. and Rodahl, K. 'Textbook of Work Physiology', New York, McGraw Hill, 1977

13 Gibbons, J.D. 'Non-parametric methods of quantitative analysis', London, Rinehart and Winston, 1976

14 Saltin, B. and Åstrand, P.-O. Maximal oxygen uptake in athletes J Appl Physiol 1967, 23, 353-358

15 Hurley, B., Hagberg, J.M., Allen, L.K., Seals, D.R., Young, J.C., Caddchee, R.W. and Holloszy, J.O. Effect of training on blood lactate levels during submaximal exercise J Appl Physiol 1984, 56, 1260-1264

16 Henritze, J., Weltman, A., Schurrer, R.L. and Barlow, $K$. Effects of training at and above the lactate threshold on the lactate threshold and maximum oxygen uptake. Euro J Appl Physiol 1985, 54, 84-88

17 Louhevaara, V., Ilanarimen, J. and Oga, P. Comparisons of the Astrand nomogram and the WHO extrapolation methods for estimaton of maximal oxygen uptake Scand J Sports Sci 1980, 2, 21-25

18 Teraslinna, P., Ismail, A.H. and McLeod, D.F. Nomogram by Astrand and Rhyming as a predictor of maximum oxygen uptake. J Appl Physiol 1966, 21, 515516

19 Sjödin, B. and Svedenhag, J. Applied physiology of marathon running Sports Medicine 1985, 2, 83-99

20 Shephard, R.J., Allen, C., Benade, A.J.S., Davies, A.T.M., di Prampero, P.E., Hedman, R., Merriman, J.E., Myhre, K. and Simmons, R. Standardisation of submaximal exercise tests World Health Organisation Bulletin 1968, 38, 765-775 